\title{
Zygotic degradation of two maternal Cdc25 mRNAs terminates Drosophila's early cell cycle program
}

\author{
Bruce A. Edgar and Sanjeev A. Datar ${ }^{1}$ \\ Division of Basic Sciences and ${ }^{1}$ Molecular and Cellular Biology Program, Fred Hutchinson Cancer Research Center, \\ Seattle, Washington 98104 USA
}

In Drosophila embryos the maternal/zygotic transition (MZT) in cell cycle control normally follows mitosis 13. Here we show that this transition requires degradation of two maternal mRNAs, string and twine, which encode Cdc25 phosphatases. Although twine is essential for meiosis and string is essential for most mitotic cycles, the two genes have mutually complementing, overlapping functions in the female germ line and the early embryo. Deletion of both gene products from the female germ line arrests germ-line development. Reducing the maternal dose of both products can lower the number of early embryonic mitoses to 12 , whereas increasing maternal $\mathrm{Cdc} 25^{\text {twine }}$ can increase the number of early mitoses to 14 . Blocking the activation of zygotic transcription stabilizes maternal string and twine mRNAs and also allows an extra maternal mitosis, which is Cde25 dependent. We propose that Drosophila's MZT comprises a chain reaction in which (1) proliferating nuclei deplete factors (probably mitotic cyclins) required for cell cycle progression; (2) this depletion causes the elongation of interphases and allows zygotic transcription; (3) new gene products accumulate that promote degradation of maternal mRNAs, including string and twine; and (4) consequent loss of Cdc25 phosphatase activity allows inhibitory phosphorylation of Cdc2 by Dwee1 kinase, effecting G2 arrest. Unlike timing or counting mechanisms, this mechanism can compensate for losses or additions of nuclei by altering the timing and number of the maternal cycles and thus will always generate the correct cell density at the MZT.

[Key Words: Drosophila embryos; maternal/zygotic transition; cell cycle control; Cdc25 mRNAs]

Received April 22, 1996; revised version accepted June 25, 1996.

The earliest cell cycles of animal development are driven by maternal gene products. During a period that has been called the midblastula transition (MBT) in Xenopus, but which we refer to more generally as the maternal/zygotic transition (MZT), one or more of these products is degraded, and the embryo becomes dependent on zygotic gene expression for further cell cycles. Although an MZT for cell cycle control is a universal feature of embryogenesis, it proceeds differently in different species. In mice the transition occurs at the two-cell stage (Schultz 1993; Wickramasinghe et al. 1995|, and in embryos with asymmetric cleavages such as nematodes, leeches, and sea urchins, the MZT probably occurs after different numbers of cycles in different cell lineages (L.G. Edgar et al. 1994; Bissen 1995). In the large, yolky eggs of fish, amphibians, and many invertebrates the MZT occurs after 10-14 rapid cleavage divisions and is coordinated with other developmental processes such as transcriptional activation and gastrulation (Kane et al. 1992; Yasuda and Schubiger 1992; Frederick and Andrews 1994).

Drosophila's MZT for cell cycle control occurs during interphase 14 (Foe et al. 1993). Before this stage the embryonic nuclei cycle metasynchronously in a syncytium and do not require transcription for cell cycle progression. The first 10 cycles are very rapid $(8 \mathrm{~min})$ but subsequent cycles lengthen progressively by the elongation of interphases (cycle $11=10 \mathrm{~min}$; cycle $12=12 \mathrm{~min}$; cycle $13=21 \mathrm{~min} ;$ at $25^{\circ} \mathrm{C}$; Foe and Alberts 1983). After the thirteenth mitosis a 45 min $S$ phase ensues $\left(S_{14}\right)$, during which the syncytial nuclei cellularize. This is followed by the first extended G2 period (G2 $\left.2_{14} \geqslant 30 \mathrm{~min}\right)$. Mitosis 14 , which coincides with gastrulation, is the first cell cycle event to be triggered by zygotic gene expression. This and subsequent mitoses progress according to patterns which are driven by pulses of transcription of Cdc25 $5^{\text {string }}$, a phosphatase that activates the mitotic kinase, Cdc2, through dephosphorylation at threonine 14 (T14) and tyrosine 15 (Y15) (Edgar and O'Farrell 1989; Foe 1989; Coleman and Dunphy 1994; Edgar et al. 1994a).

Several mechanisms have been proposed to explain the changes in cell cycle kinetics which occur during the MZT. Almost all of these involve the progressive titration or depletion, by dividing nuclei, of some maternal factor required for cell cycle progression. These models are all derived from experiments showing that altering 
the nucleo/cytoplasmic ratio affects cell cycle timing and number. Experimental manipulations that increase the nucleo/cytoplasmic ratio slow the maternal cell cycle oscillator prematurely and advance the MZT by one or even two cell cycles in a variety of different embryo types. Decreasing the nucleo/cytoplasmic ratio has the opposite effect: Rapid cell cycles continue for longer, and the MZT occurs after more cycles than normal (Okada et al. 1980; Kobayakawa and Kubota 1981; Newport and Kirschner 1982a,b; Mita 1983; Mita and Obata 1984; Edgar et al. 1986; Dasso and Newport 1990; Yasuda et al. 1991).

The molecules at the root of this relationship have remained obscure. Dasso and Newport (1990) proposed that in Xenopus, titration of a DNA replication factor causes the elongation of $\mathrm{S}$ phases, and delays mitoses by activating an S/M checkpoint control that inhibits Cdc2. In Xenopus this checkpoint arrest involves inhibition of $\mathrm{Cdc} 2$ by phosphorylation at $\mathrm{Y} 15$, suggesting that the kinase (Weel) and phosphatase (Cdc25) that regulate this modification might play a role in the MZT /Ferrell et al. 1991; Smythe and Newport 1992; Hoffmann and Karsenti 1994). Studies in Drosophila, however, are inconsistent with this model because: (1) experiments using DNA replication inhibitors show that the $S / M$ checkpoint is not effective until interphase 14, just after the MZT (Raff and Glover 1988; Foe et al. 1993; Debec et al. 1996; B.A. Edgar, unpubl.), and (2) Y15 phosphorylation of Cdc2 first occurs during interphase 14, rather than during cycles $10-13$, when interphases begin to lengthen (Edgar et al. 1994b).

Clues to how Drosophila's MZT is initiated come from studies of how the Cdc2 kinase is regulated in the early embryo. Genetic tests have confirmed the requirement for Cdc2 in these cycles (Stern et al. 1993) and, as in other systems, Cyclins A and B are its obligatory activating subunits (Lehner and O'Farrell 1989, 1990b). Prior to cycle 8 these cyclins are constitutively present, and $\mathrm{Cdc} 2$ kinase appears to remain active through all phases of the cycle (Edgar et al. 1994b). Beginning with cycle 9 however, a progressive increase in the degradation of cyclins at mitosis coincides with transient inactivations of Cdc2, and interphases begin to lengthen. Chromosomal deficiencies that reduce the maternal dose of Cyclin A and Cyclin B can elongate cycles 10-13, suggesting that a cyclin synthesis limitation may cause the normal lengthening of interphases during this period (Edgar et al. 1994b). The progressive increase in cyclin degradation is coupled to multiplication of some component of the mitotic apparatus that targets cyclins for destruction, most likely mitotic spindles. Thus, earlier models that explained slowing of the maternal cycles as a depletion of cytoplasmic factors by nuclei might be understood in terms of a depletion of maternal cyclins by proliferating nuclei and spindles. But cyclin depletion cannot explain the G2 arrest that occurs in cycle 14 . Maternal cyclin mRNAs perdure through interphase 14 (Lehner and O'Farrell 1989, 1990b), and cyclins accumulate to very high levels early in this cycle. If cyclins were limiting at this stage, they should trigger a synchronous mitosis just after $S$ phase $14\left(\sim 45 \mathrm{~min}\right.$ after $\left.M_{13}\right)$, but this does not happen.

Previous studies have suggested that degradation of maternal Cdc25 may be the critical event that inactivates the maternal cell cycle oscillator. For instance, the maternal mRNAs encoding both of Drosophila's two $\mathrm{Cdc} 25$ products (Cdc $25^{\text {string }}$ and $\left.\mathrm{Cdc} 25^{\text {twine }}\right)$ are degraded abruptly during the first $30 \mathrm{~min}$ of interphase 14 and are not replaced by zygotically transcribed Cdc $25^{\text {string }}$ until the end of this cycle (Alphey et al. 1992; Courtot et al. 1992; Edgar et al. 1994a). In contrast, maternal contributions of all other known cell cycle regulators (such as Cyclins A, B, D, E, Cdc2, and Cdc2c) perdure in excess through cycle 14, and thus should not limit cell cycle progression at this stage (Lehner and O'Farrell 1989, 1990a; Stern et al. 1993; Sauer et al. 1995; Finley et al. 1996). Coincident with the loss of maternal Cdc25 during interphase $14, \mathrm{Cdc} 2$ kinase begins to accumulate in the inactive, Y15-phosphorylated form for the first time (Edgar et al. 1994b). Moreover, forced expression of either Cdc25 $5^{\text {string }}$ or a non-phosphorylatable, string-independent form of Cdc2 (Cdc2 T14A, Y15F) is sufficient to override the $\mathrm{G}_{14}$ arrest and trigger mitosis 14 prematurely throughout the embryo (Edgar and O'Farrell 1990; N. Yakubovich, P. Leopold and P. O'Farrell, pers. comm.). These compelling correlations prompted us to test whether degradation of maternal Cdc25 string and $\mathrm{Cdc} 25^{\text {twine }}$ is what shuts off the maternal cell cycle oscillator in $\mathrm{G} 2_{14}$.

\section{Results}

Blocking transcriptional activation bypasses the MZT

Drosophila embryos support very little transcription prior to nuclear cycle 10 (Anderson and Lengyel 1979, 1980; Edgar and Schubiger 1986; Pritchard and Schubiger 1996). To test the role of zygotic transcription in the early cell cycles, we injected the RNA polymerase II inhibitor, $\alpha$-amanitin, into embryos before cycle 6 . After this injection, nuclear divisions continued normally through mitosis 13 , indicating that transcription is not essential for these cell cycles (see also $\mathrm{O}^{\prime}$ Farrell et al 1989; Foe et al. 1993). Even more interesting, $\alpha$-amanitin injected embryos underwent an extra syncytial mitotic wave that occurred $44 \pm 12 \min (n=45)$ after mitosis 13 . This time corresponds to the S/G2 boundary (Edgar and Schubiger 1986), and since checkpoint controls prevent mitosis prior to the completion of DNA replication at this stage (Foe et al. 1993), this may be the earliest time when mitosis 14 can be induced. Analysis of living embryos and of fixed embryos stained for DNA and microtubules showed that during this unusual 14th mitosis nuclear envelope breakdown, spindle formation, and chromosome condensation and segregation all occurred. However, multipolar spindles were common and re-establishment of interphase was abnormal, showing frequent fusion of adjacent telophase nuclei (Fig. 1). This may be attributable to the lack of zygotic products normally required to regulate the cytoskeleton; in fact, the 

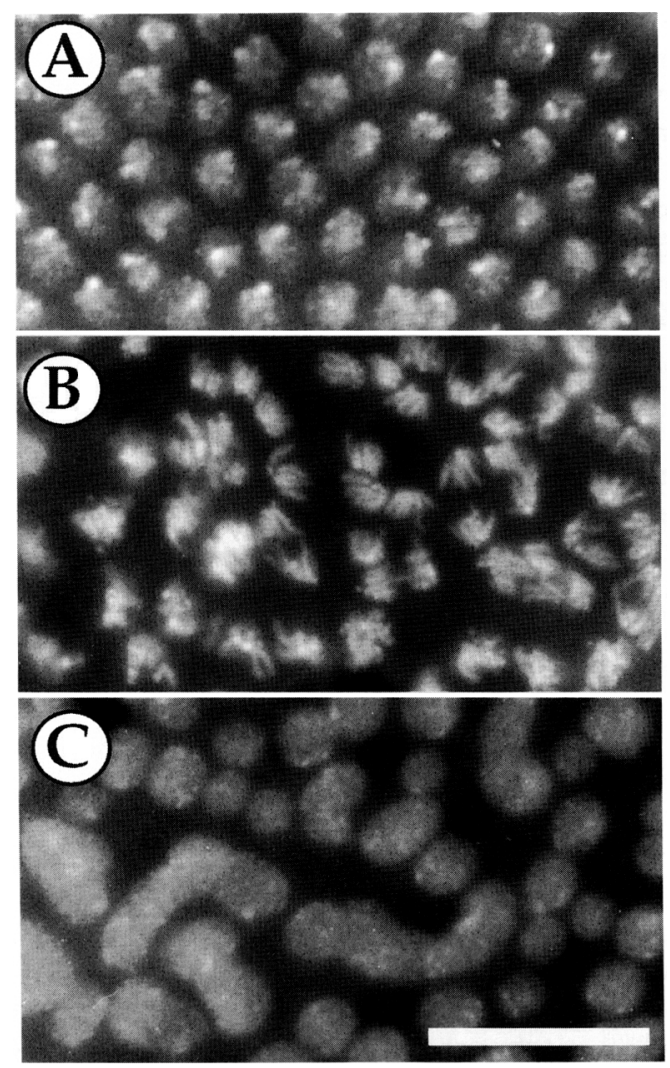

Figure 1. An extra syncytial mitosis occurs when transcriptional activation is blocked. Embryos were injected with $\alpha$-amanitin prior to cycle 6 , incubated until cycle 14 , and then fixed and stained for DNA. (A) The normal, cycle 14 nuclear density achieved prior to the extra division. $(B)$ Condensed chromosomes and the haphazard chromosome segregation that occurs during the extra division. $(C)$ Fused, irregularly-spaced nuclei during the interphase that follows the extra division. All panels are the same magnification; scale bar, $20 \mu \mathrm{M}$.

earliest visible effect of $\alpha$-amanitin is to block cellularization of the blastoderm during cycle 14 . The additional maternal mitosis caused by $\alpha$-amanitin indicates that zygotic transcription is required to inactivate the maternal cell cycle oscillator.

\section{Zygotic gene products trigger degradation of maternal Cdc25 mRNAs}

Normally both maternal string and maternal twine mRNA are degraded abruptly during the first $30 \mathrm{~min}$ of interphase 14 (Figs. 2A,B and $3 \mathrm{C}$ ). In embryos injected with $\alpha$-amanitin prior to cycle 6 , both mRNAs persisted at high levels for at least $2 \mathrm{hr}$ after the time they are normally degraded $(\alpha \mathrm{A} @ 6$; Fig. 2A,B). The stabilization of string and twine mRNA was highly reproducible, but required that the $\alpha$-amanitin be injected throughout the embryo before cycle 6 . Under these conditions we noted significant stabilization in four of four independent experiments. When $\alpha$-amanitin was injected during cycle 13 , after the onset of zygotic transcription, degradation of the string and twine mRNAs occurred as in controls, and both mRNAs were virtually undetectable $1 \mathrm{hr}$ after the injection $(\alpha \mathrm{A} @ 13$; Fig. 2A,B). Under these conditions no extra mitoses occurred. These results indicate that transcription of some genes that are critical for degradation of maternal string and twine mRNAs begins between cycle 6 and cycle 13 .

\section{Inhibitory phosphorylation of Cdc2 is delayed when transcriptional activation is blocked}

To confirm that the extra, $\alpha$-amanitin-induced mitotic wave involved maternal Cdc 25 phosphatase activity, we assayed the phosphorylation of Cdc2 in $\alpha$-amanitin injected embryos (Fig. 2C). We found that embryos injected with $\alpha$-amanitin prior to cycle 6 had reduced levels of Y15-phospho-Cdc2, and low but detectable levels of unphosphorylated-Cdc2 and T161-phospho-Cdc2 (the active form) during the extra mitotic wave. Control embryos, which were injected with $\alpha$-amanitin during cycle 14, did not undergo an extra division and contained only the Y15-phosphorylated forms of Cdc2. This observation is consistent with the idea that the $\alpha$-amanitin-induced mitosis is driven by the action of stabilized maternal Cdc25 phosphatases on Cdc2.

\section{Degradation of Cdc25 $5^{\text {string }}$ protein is cell cycle dependent}

In contrast to string mRNA, which is stable until cycle 14, Cdc2 $5^{\text {string }}$ protein reaches peak levels at about cycle 10 and is depleted thereafter (Fig. 3A). This suggests that turnover of the protein might be regulated differently than that of the mRNA. To determine the requirements for degradation of $\mathrm{Cdc} 25^{\text {string }}$ protein, we performed immunoblots on embryos injected prior to cycle 6 with several inhibitors (Fig. 4). Unlike string mRNA, $\mathrm{Cdc} 25^{\text {string }}$ protein was degraded on schedule after $\alpha$-amanitin injection. However, both colcemid (which blocks the cycle in mitosis) and aphidicolin (which blocks DNA replication) stabilized maternal Cdc25 $5^{\text {string }}$. This suggested that degradation of $\mathrm{Cdc} 25^{\text {string }}$ protein could be cell cycle dependent, an idea that was tested and confirmed as described below.

First, string expression was induced in embryos at a variety of developmental stages using the heat inducible hsp70-stg3 transgene (Edgar and O'Farrell 1990), and the expression patterns of string mRNA and protein were assessed in situ. We confirmed that string mRNA in this experiment was expressed ubiquitously at all stages (not shown). However, only cells in M, S, and G2 phases of the cycle accumulated the $\mathrm{Cdc} 25^{\text {string }}$ protein (Fig. 5A). Cells in G1, which first arise in the epidermis following mitosis 16, failed to accumulate Cdc $25^{\text {string }}$ protein (Fig. $5 \mathrm{~B}$ ). Consistent with this observation, these $\mathrm{Gl}_{17}$ epidermal cells normally express high levels of string mRNA but very low levels of the Cdc2 $5^{\text {string }}$ protein for about the first $2 \mathrm{hr}$ of Gl (Edgar et al. 1994a,b). Thus, during $\mathrm{Gl}_{17}$, either string mRNA is not translated, or $\mathrm{Cdc} 25^{\text {string }}$ protein is very unstable. 

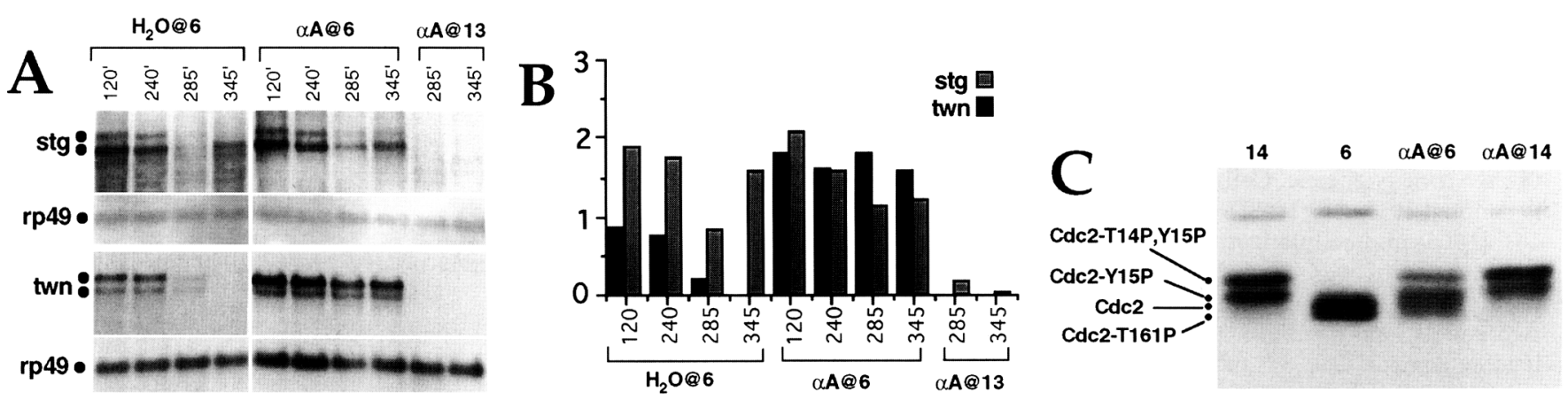

Figure 2. Zygotic transcription promotes degradation of Cdc25 mRNAs and Y15 phosphorylation of Cdc2. $(A)$ Embryos from a single 15 -min collection were injected in parallel with either water $\left(\mathrm{H}_{2} \mathrm{O}\right)$ or $\alpha$-amanitin $(\alpha \mathrm{A})$ prior to cycle 6 , or at cycle 13 , and incubated until the times indicated in minutes (') after egg deposition. RNA was then prepared and analyzed by Northern analysis using probes to string (stg), twine (twn), and ribosomal protein 49 (rp49). (B) Densitometric quantitation of these gels (see Materials and methods). Developmental staging in the control $\mathrm{H}_{2} \mathrm{O}$-injected embryos was the following: 120 min, cycles $9-11 ; 240$ min, syncytial cycle $14 ; 285$ min, mid-cellularization cycle $14 ; 345$ min, early stages of gastrulation. In controls $\left(\mathrm{H}_{2} \mathrm{O}\right)$, maternal stg and $t w n$ RNAs are degraded before $285 \mathrm{~min}$, and replaced by new zygotic stg transcripts by $345 \mathrm{~min}$. Injection of $\alpha$-amanitin at cycle 6 stabilizes maternal stg and $t w n$ transcripts, whereas injection at cycle 13 allows their degradation. The slower migrating stg transcript is expressed maternally but not zygotically. $(C)$ The four phosphoisoforms of Cdc2 as detected by immunoblotting with anti-Cdc2 antibodies (Edgar et al. 1994b). In late cycle 14 embryos (14) only the two Y15-phosphorylated forms of Cdc2 are detected (top two bands). In cycle 6 embryos (6) only unphosphorylated Cdc2 $(\mathrm{Cdc} 2)$ and the active form $(\mathrm{Cdc} 2-\mathrm{T} 161 \mathrm{P})$ are detected (bottom two bands). Experimental embryos $(\alpha \mathrm{A} @ 6)$ were injected with $\alpha$-amanitin prior to cycle 6 and injected with colcemid just after mitosis 13. Colcemid arrests the cell cycle in mitosis and was used to synchronize the injected embryos as they arrested in the $\alpha$-amanitin-induced fourteenth mitosis. Control embryos $|\alpha \mathrm{A} @ 14|$ were injected with $\alpha$-amanitin and colcemid just after mitosis 13 and homogenized for SDS-PAGE at the same time as the experimental embryos (55 min after mitosis 13). The experimental embryos $(\alpha \mathrm{A} @ 6)$ show all four phosphoisoforms of Cdc2, including small amounts of active Cdc2-T161P. Control embryos $(\alpha \mathrm{A} @ 14)$ show only inactive, Y15-phospho-Cdc2.

As a further test of the cell cycle dependence of Cdc25 $5^{\text {string }}$ expression, $\mathrm{Gl}_{17}$ epidermal cells were driven into an unscheduled $\mathrm{S}$ phase by inducing Cyclin $\mathrm{E}$ expression using the $h s p 70-C y c E$ transgene (Knoblich et al. 1994). As these cells entered $S$ phase they accumulated high levels of $\mathrm{Cdc} 25^{\text {string }}$ protein, presumably derived from the mRNA that is normally expressed at this stage (Fig. 5D). This is consistent with a stabilization of the $\mathrm{Cdc} 25^{\text {string }}$ protein as G1 cells enter S phase.

Finally, the effect of mitotic arrest on Cdc25 $5^{\text {string }}$ protein was assessed by injecting colcemid into embryos during the postblastoderm divisions, and then incubating them for $1-3 \mathrm{hr}$ prior to fixation. Colcemid blocks cells in mitosis, but does not block other cell cycle transitions. We observed that cells blocked in mitosis by colcemid all had very high levels of Cdc25 $5^{\text {string. With }}$ longer incubations, more cells became $\mathrm{Cdc} 25^{\text {string }}$ positive, and the spatial distributions of these cells always matched the spatial pattern of cell divisions (Fig. 5F). This indicates that $\mathrm{Cdc} 25^{\text {string }}$ protein is stable during $M$ phase.

All of these observations suggest that $\mathrm{Cdc} 25^{\text {string }}$ protein is stable during $S, G 2$, and M phases, is destabilized as cells leave mitosis, and remains unstable through G1. However, cell cycle phase-specific translation of string mRNA is also a tenable explanation for our observations. Interestingly, Cdc25 $5^{\text {string's }}$ behavior in these experiments is identical to that of the G2/M cyclins, which are believed to be subject to ubiquitin-dependent degradation beginning at metaphase/anaphase and continuing through G1 in both Drosophila and Saccharomyces ce- revisiae (Amon et al. 1994; Knoblich et al. 1994). Accordingly, we propose that $\mathrm{Cdc} 25^{\text {string }}$ may be targeted for degradation in a manner similar to G2/M cyclins.

\section{Maternal Cdc25 $5^{\text {string }}$ is dispensable}

To test the function of maternal Cdc $25^{\text {string }}$ during cell cycles 1-13, we generated clones of string mutant cells in the female germline using the FLP/FRT/ovo ${ }^{D 1}$ method (Chou et al. 1993; Xu and Rubin 1993). Five severe loss-of-function alleles of string (7B, 3A1, AR2, AR4, and AR5) and one temperature-sensitive allele (9A) were used. We confirmed that the FLP/FRT/OVO ${ }^{D}$ method actually deletes maternal Cdc25 $5^{\text {string }}$ protein from the early embryo by performing immunoblots on embryos from maternal germ lines homozygous for $s t g^{3 A 1}$ and $s t g^{A R 4}$, which are near null alleles for transcription (Fig. 3B). We then studied the cell cycles in these embryos. To our surprise, embryos lacking maternal Cdc $25^{\text {string }}$ proceeded through cycles 1-13 normally, and always traversed the MZT during interphase $14 \mathrm{Ta-}$ ble 1). When we timed cycles 11-13 in embryos derived from $\mathrm{stg}^{7 B} / \mathrm{stg}^{7 B}$ germ lines, we found no significant deviations from the normal cycle timing (cycle $11=11 \pm 1^{\prime}$; cycle $12=14 \pm 2^{\prime}$; cycle $13=22 \pm 3^{\prime} ; n=10$ ). We conclude that $\mathrm{Cdc} 25^{\text {string }}$ is required for neither female germ cell divisions, nor embryonic cell cycles 1-13.

Cdc25 string and Cdc25 $5^{\text {twine }}$ complement each other in the germ-line and early embryo

These unexpected results suggested that $\mathrm{Cdc} 25^{\text {twine }}$ 
Figure 3. Cdc25 protein and mRNA levels after manipulations of maternal gene dosage. (A) Immunoblot time courses of $\mathrm{Cdc} 25^{\text {string }}\left(\mathrm{Cdc}^{2} 5^{\text {stg }}\right)$ expression in embryos from females with one or six copies of the string (stg) gene. Cell cycle number is denoted at the top (14S) Syncytial cycle $14 ;(14 \mathrm{C})$ mid-cellularization cycle 14 . Three embryos were loaded per lane, exposure times were equivalent between the two panels, and $\beta$-tubulin is shown as a loading control. Cdc $25^{\text {stg }}$ protein levels as quantified by densitometry are graphed below. Note that the overexpressed protein is still degraded at the normal time. (B) The lack of $\mathrm{Cdc} 25^{\text {stg }}$ protein in embryos from $\mathrm{stg} / \mathrm{stg}$ mutant germ lines. One pre-cycle 8 embryo was loaded per lane. stg ${ }^{A R 4}$ and $s \operatorname{sg}^{3 A 1}$ are P-element insertion alleles that impair but do not completely block transcription; thus, small amounts of $\mathrm{Cdc} 25^{\text {stg }}$ protein are detected. (C) Time courses of stg and twine (twn) mRNA expression, by Northern blot, through the early cycles in embryos with either two or six gene copies of stg (top) or twn (bottom). Relative RNA levels as measured by densitometry are graphed below. Embryo stages are designated as preblastoderm (PB); syncytial blastoderm, cycles 11,12 (SB); syncytial cycle $14(14 \mathrm{~S})$; mid-cellularization cycle $14(14 \mathrm{C})$; early gastrulation cycle $14(14 \mathrm{G})$; germ band-extended cycle $15(15)$. Ribosomal protein 49 (rp49) mRNA is shown as a loading control. Note that the overexpressed mRNAs are degraded at the normal stage.

might play a role in germ cell and early embryonic mitoses, as well as in meiosis as reported previously (Alphey et al. 1992; Courtot et al. 1992). Such a role is plausible since maternal twine mRNA persists in the egg through the first 13 mitoses and is degraded at the same time as string mRNA (Figs. $2 \mathrm{~A}$ and $3 \mathrm{C}$ ). Moreover, $\mathrm{Cdc} 25^{\text {string }}$ and $\mathrm{Cdc} 25^{\text {twine }}$ appear to have overlapping phosphatase function because they can both complement the cdc25-22 mutation in Schizosaccharomyces pombe (Edgar and O'Farrell 1989; Alphey et al. 1992). We tested the requirement for twine in the early mitotic cycles by injecting nuclei from wild-type embryos into embryos from $t w n^{H B S} / t w n^{H B S}$ females. These embryos arrest early in development because of a defective female meiosis and do not support proliferation of endogenous nuclei (White-Cooper et al. 1993). Wild-type nuclei injected into these $t w n^{H B 5}$ embryos, however, proliferated avidly, and $23 / 118$ of the injected embryos formed partial or complete blastoderms (not shown). $0 / 72$ control $t w n^{H B 5}$ embryos, which were not injected with nuclei, formed blastoderms. The proliferation of injected nuclei in embryos lacking Cdc $25^{\text {twine }}$ suggests that, like string, twine is not required for the early cycles. We note, however, that these injected, proliferating nuclei always arrested in a terminal interphase at a nuclear density equivalent to cycle 11 or 12 , and never populated the $t w n^{H B 5}$ embryos to the cycle 14 nuclear density. Whereas the reason for this early cell cycle arrest is unclear, it might imply that maternal Cdc $25^{\text {twine }}$ is essential to achieve cycle 14 .

In any case, these findings suggested that $\mathrm{Cdc} 25^{\text {string }}$ and $\mathrm{Cdc} 25^{\text {twine }}$ might have overlapping functions in the early embryo. To test this idea, we made $s \mathrm{tg}^{7 B} / \mathrm{stg}^{7 B}$ germ line clones in $t w n^{H B 5} / t w n^{H B 5}$ females. When string and twine were simultaneously deleted, germ cell proliferation was blocked and no ovarioles or eggs were produced. Because germ cells homozygous for either string or twine alone proliferate and produce abundant eggs, this result indicates that $\mathrm{Cdc} 25^{\text {string }}$ and $\mathrm{Cdc} 25^{\text {twine }}$ have mutually complementing functions in the germ line, most probably in germ cell proliferation. Because neither product appeared to be required for the early embryonic mitoses, it seemed likely that the two gene products complement each other in these cycles as well. This idea is supported by the results of dosage experiments, described below.

Lowering the maternal dose of Cdc25 string and Cdc25 ${ }^{\text {twine }}$ can advance the MZT

When we studied embryos lacking maternal string and having one, rather than two doses of maternal twine, we 


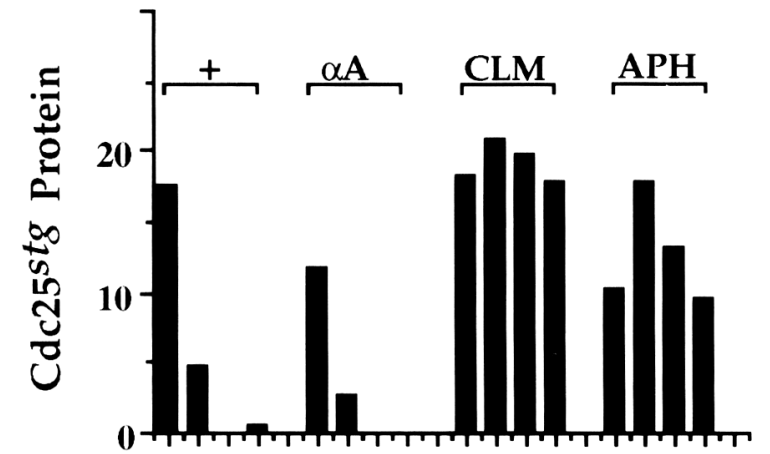

hrs AED: $12341234 \quad 1234 \quad 1234$

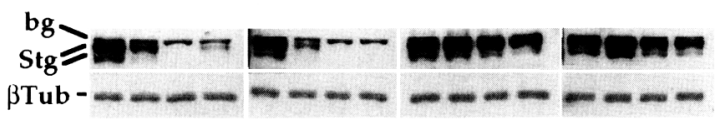

Figure 4. Degradation of maternal Cdc25 string $\{\mathrm{Stg} \mid$ protein is cell cycle dependent. Embryos were injected with $\mathrm{H}_{2} \mathrm{O}(+)$, $\alpha$-amanitin $(\alpha \mathrm{A})$, colcemid $(\mathrm{CLM})$, or aphidicolin $|\mathrm{APH}\rangle$ prior to cycle 6 , incubated for the times indicated, and then assayed for $\mathrm{Cdc} 25^{\text {string }}$ protein by immunoblotting (below). In this experiment, developmental staging in the $\mathrm{H}_{2} \mathrm{O}$-injected control embryos was the following: (1 hr AED) Cycles 5-7; ( 2 hr) cycles $12-13$; $(3 \mathrm{hr})$ mid-cellularization cycle $14 ;(4 \mathrm{hr})$ early gastrulation cycle 14 . Control and $\alpha$-amanitin-injected embryos continued to cycle after injection, whereas colcemid-injected and aphidicolin-injected embryos suffered a rapid cell cycle arrest. Protein levels (above) were quantified by scanning densitometry and normalized for $\beta$-tubulin ( $\beta$ Tub). The thin, uppermost band (bg) is a cross-reacting protein that is detected even in embryos deleted for the string gene. Note that $\mathrm{Cdc} 25^{\text {string }}\langle\mathrm{Stg}|$ was degraded normally in $\alpha$-amanitin-injected embryos but was stabilized in the colcemid- or aphidicolin-injected embryos.

noted an interesting cell cycle defect. Of 89 embryos, 11 cellularized and gastrulated during interphase 13 , rather than interphase 14 (Figs. 6A and 7A; Table 1). Another $7 / 89$ cellularized as mosaics in which part of the blastoderm arrested in cycle 14 and another part arrested in cycle 13 (Fig. 7B). Immunoblotting of Cdc2 from these cellularizing, cycle 13 embryos confirmed that $\mathrm{Cdc} 2$ does indeed accumulate in the inactive, Y15 phosphorylated form during the extended interphase 13 (not shown). Y15-phospho-Cdc2 is never detected during cycle 13 in wild-type embryos (Edgar et al. 1994b). Thus the premature cell cycle arrest in embryos from $t w n^{H B S} /+$; $s \mathrm{sg}^{7 B} / \operatorname{stg}^{7 B}$ germ lines is correlated with reduced Cdc25 function.

\section{Increasing Cdc25 $5^{\text {twine }}$, but not $C d c 25^{\text {string }}$, can postpone the MZT}

To test the role of Cdc25 levels in the MZT further, we varied the maternal gene dosage. string dosage was increased by adding four copies of string transgenes that are expressed maternally (Edgar et al. 1994a). Immunoblots and Northern blots confirmed that embryos derived from females carrying these transgenes, which have 6 copies of string, contained substantially more string $\mathrm{mRNA}$ and protein than embryos from wild-type females, which have two copies of string (Fig. 3A,C). However, these additional string products were degraded according to normal kinetics, and time lapse video analysis showed that the $6 x$ string embryos had normal timing of cycles $10-13$ (cycle $11=11 \pm 1^{\prime}$; cycle $12=14 \pm 2^{\prime}$; cycle $13=22 \pm 4^{\prime} ; n=7$. . Moreover, the $6 x$ string embryos always accomplished the MZT during the correct cycle: interphase 14 (Table 1).

The maternal dose of Cdc $25^{\text {twine }}$ was increased similarly from two to six gene copies by introducing four transgenes encoding twine, driven by its own promotor (Alphey et al. 1992). Northern blots showed that embryos derived from $6 \mathrm{x}$ twine females had substantially more twine mRNA than those from wild-type ( $2 x$ twine) females. However, this extra twine mRNA was also degraded with normal kinetics (Fig. 3C). Nevertheless, we found that a small fraction $(5 \%)$ of these $6 x$ twine embryos experienced an extra, 14th mitotic wave prior to cellularization (Figs. 6C and 7D; Table 1). This extra mi-

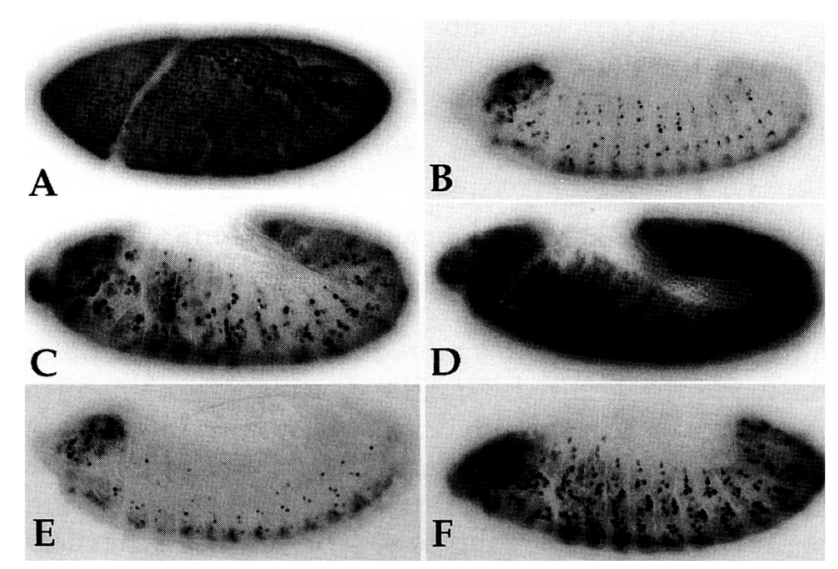

Figure 5. Zygotic Cdc25 string protein accumulates in S, G2, and $M$ phases, but not in Gl. All embryos are immunohistochemically stained for $\mathrm{Cdc} 25^{\text {string }}$ protein. In $(A)$ and $(B)$, string mRNA was ubiquitously overexpressed using a heat-inducible transgene (hsp70-stg3). Cells in the cycle 14 embryo $(A)$ are in $\mathrm{M}, \mathrm{S}$, and G2 phases, and all express Cdc $25^{\text {string }}$ protein. Most of the epidermal cells in the cycle 17 embryo $(B)$ are in G1 and do not express Cdc $25^{\text {string }}$ protein despite high levels of the cognate mRNA (not shown), and Cdc $25^{\text {string }}$ protein accumulates only in cycling neuroblasts, which have no Gl phases (Weigmann and Lehner 1995). $(C, D)$ The effect of driving G1-arrested epidermal cells into $\mathrm{S}$ phase by heat shock induction of the $h s p 70$ CycE transgene. Both embryos were heat-shocked: $C$ is wild type; $D$ carries the $h s-C y c E$ gene. At this developmental stage, endogenous string transcripts are expressed throughout the epidermis; driving these cells from G1 into $S$ phase by induction of Cyclin $\mathrm{E}$ evidently allows accumulation of $\mathrm{Cdc} 25^{\text {string }}$ protein derived from these transcripts. $(E, F)$ The effect of blocking cells in $M$ phase by colcemid injection. Embryo $F$ was injected with colcemid 2 hr prior to fixation; embryo $E$ is its control, injected with water $2 \mathrm{hr}$ prior to fixation at the same stage. Note that the colcemid-injected embryo $F$ has many more $C d c 25^{\text {string }}$-positive cells. These are cycling neuroblasts that have arrested in $M$ phase. 
Table 1. Altering maternal Cdc25 dose or blocking zygotic transcriptional activation alters the cycle at which MZT occurs

\begin{tabular}{lcrrrr}
\hline \multirow{2}{*}{$\begin{array}{l}\text { Maternal Cdc25 } \\
\text { dose }\end{array}$} & Inject & 15 & 14 & 13 & $(N)$ \\
\cline { 2 - 5 } & - & 5 & 95 & 0 & $(105)$ \\
\hline 6x twn, 2x stg & - & 4 & 96 & 0 & $(54)$ \\
$4 x$ twn, 2x stg & $\alpha \mathrm{A}$ & 88 & 12 & 0 & $(51)$ \\
$2 x$ twn, 2x stg & - & 0 & 100 & 0 & $(50)$ \\
$2 x$ twn, 6x stg & - & 0 & 100 & 0 & $(73)$ \\
$2 x$ twn, 2x stg & $\alpha \mathrm{A}$ & 0 & 100 & 0 & $(52)$ \\
$1 \times$ twn, 1x stg & - & 0 & 100 & 0 & $(80)$ \\
$1 \times$ twn, 1x stg & - & 0 & 100 & 0 & $(67)$ \\
$2 x$ twn, 0x stg & - & 0 & 84 & 16 & $(89)$ \\
$1 x$ twn, 0x stg & - & - & - & - & $(0)^{*}$ \\
Ox twn, 0x stg & - & &
\end{tabular}

Dosage of string was reduced using the FLP/FRT/ovo ${ }^{D 1}$ method to generate germ-line clones of $\operatorname{stg}^{7 B} / \mathrm{stg}^{7 B}$. In some cases, $\alpha$-amanitin was injected prior to cycle $\sigma(\alpha \mathrm{A})$. The arrest cycle was assessed either by observation of living embryos (in the case of $\alpha$-amanitin injection) or by measurements of nuclear densities in fixed, cellularizing blastoderms (other cases). $(N)$ The number of embryos scored in each experiment (see Materials and methods for complete germ-line genotypes). Where possible, balanced stocks were out-crossed to Sevelen wild types to remove balancer chromosomes and equalize genetic background. $(* 10 x$ twn, $0 x$ stg germ lines produce no eggs.

totic wave spread from the center of the embryo, rather than from the poles as do earlier mitotic waves, and almost always subsided before encompassing the entire embryo. Thus, mosaic embryos-cycle 14/15 cellular blastoderms-resulted (Fig. 7D). Unlike the $\alpha$-amanitin induced extra division, the extra division resulting from excess Cdc $25^{\text {twine }}$ was essentially normal and gave rise to evenly arrayed but very small cells. The extra division observed in $6 \mathrm{x}$ twine embryos supports the idea that degradation of twine to below a critical threshold is necessary to arrest the cell cycle in $\mathrm{G} 2_{14}$.

\section{The $\alpha$-amanitin-induced extra division requires maternal Cdc25}

To further confirm that degradation of maternal Cdc 25 is the cause of cell cycle arrest at the MZT, we wanted to know whether the extra, $\alpha$-amanitin-induced mitosis was driven by stabilized maternal string and twine (see Fig. 2). To test this we injected $\alpha$-amanitin into pre-cycle 6 embryos with one, rather than two, maternal doses of both string and twine $11 \mathrm{x}$ twine, $1 \mathrm{x}$ string; maternal genotype $=w /+; t w n^{H B S} \mathrm{cn} \mathrm{bw/t;} P\left(\mathrm{ry}^{+}\right.$hs-neo FRT]82B $P / \mathrm{w}^{+}$hs-myc/87E stg $\mathrm{g}^{7 B} /+1$. Then, expecting that the lowered levels of $\mathrm{Cdc} 25$ might prolong the interphase preceding the $\alpha$-amanitin-induced mitosis, we timed interphase 14 . We obtained a yet-more-striking result: $0 / 52$ of the $1 x$ twine, $1 x$ string embryos generated an extra mitotic wave (Table 1). Instead, all 52 remained arrested in interphase 14 until they degenerated, 180 $240 \mathrm{~min}$ after mitosis 13 . Among wild-type embryos in- jected in parallel as controls, we detected the extra division in $45 / 51,63 \pm 19 \mathrm{~min}$ after mitosis 13 . This result indicates that the $\alpha$-amanitin-induced mitosis is sensitive to $\mathrm{Cdc} 25$ dosage, and thus that it probably requires the maternal Cdc 25 mRNAs that are stabilized by $\alpha$-amanitin.

\section{Discussion}

Wild-type Drosophila embryos always have 13 rapid, synchronous, maternally driven mitoses before they arrest in their first G2 period, cellularize, and assume zygotic control the cell cycle. In the present work we show that embryos with increased maternal supplies of Cdc25 can have 14 maternally driven mitoses, whereas embryos with reduced maternal Cdc25 often have only 12 (Figs. 6, 7; Table 1). Thus maternal Cdc25 phosphatases are dosage-sensitive regulators that can determine how many mitoses occur before the transition to zygotic cell cycle control.

We also show that blocking zygotic transcriptional activation by an early injection of $\alpha$-amanitin stabilizes maternal Cdc25 mRNAs and, like raising Cdc25 dosage, allows an extra maternally driven cell cycle (Figs. 1 and 2). Although maternal Cdc $25^{\text {string }}$ protein is degraded normally after $\alpha$-amanitin injection (Fig. 4), dosage experiments suggest that $\mathrm{Cdc} 25^{\text {string }}$ and $\mathrm{Cdc} 25^{\text {twine }}$ are nevertheless required for the $\alpha$-amanitin-induced division cycle (Table 1). These apparently paradoxical results may be reconciled by the likelihood that new $\mathrm{Cdc} 25^{\text {string }}$ and/or Cdc25 $5^{\text {wine }}$ proteins are translated from the maternal mRNAs that are stabilized after $\alpha$-amanitin injection, and that these accumulate to a threshold sufficient to drive the extra division. This interpretation is consistent with our finding that the stability of Cdc $25^{\text {string }}$ protein is cell-cycle regulated (Figs. 4 and 5), and with our detection of Cdc2 that is not Y15 phosphorylated (and is presumably active) during the $\alpha$-amanitin-induced division (Fig. 2C). The simplest conclusion to be drawn from these findings is that degradation of maternal Cdc25 mRNAs is a critical event in the MZT, and that this degradation is timed by the activation of $z y-$ gotic transcription.

By drawing the present work together with earlier observations we can construct a general model that explains many aspects of the MZT (Fig. 8). The maternal cell cycle oscillator appears to be inactivated as the final event in a chain reaction that starts at fertilization. Proliferation of the embryonic nuclei is the initial driving force of this reaction: As these nuclei multiply they progressively deplete something required for cell cycle progression, and this causes lengthening of interphases starting in cycle 10 . Dosage experiments suggest that the first critical factors to be titrated out are probably mitotic Cyclins A and B (Edgar et al. 1994b), and not Cdc25 phosphatases (this paper). The amount of cyclin degraded at mitosis is proportional to the number of nuclei dividing in the embryonic cytoplasm, making cyclin depletion closely linked to nuclear proliferation. Beginning at mitosis 10 cyclins appear to be degraded to below the 

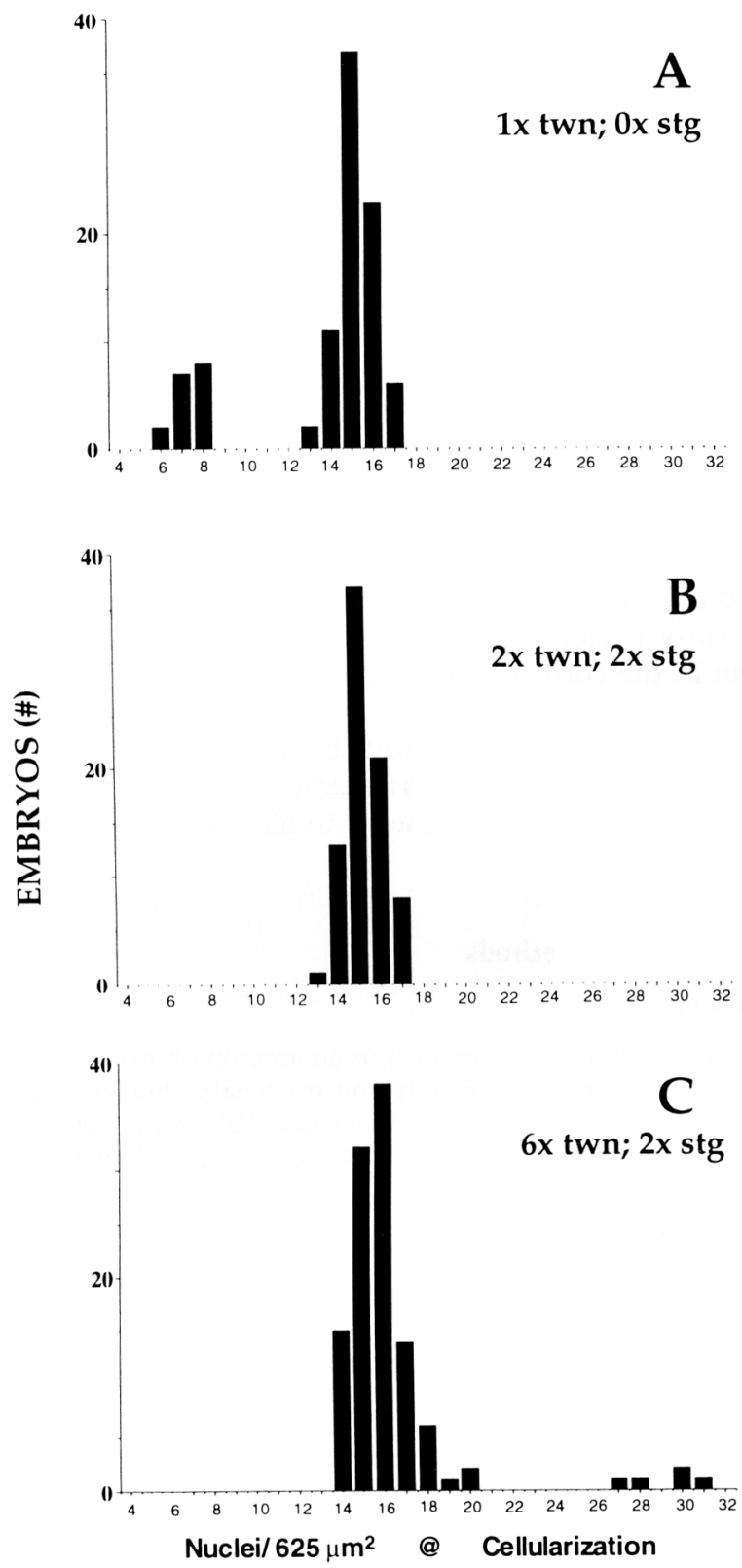

Figure 6. Cdc25 dosage determines the number of cycles prior to cellularization. Shown are nuclear densities at cellularization in embryos derived from germ lines with $1(A), 4(B)$, or $8(C)$ maternal doses of $\mathrm{Cdc} 25$. Germ-line dosage of Cdc25 is indicated within the graphs. Nuclear densities of $6-8 / 625 \mu \mathrm{m}^{2}, 14$ $18 / 625 \mu \mathrm{m}^{2}$, and $27-32 / 625 \mu \mathrm{m}^{2}$ correspond to cycles 13,14 , and 15, respectively. Embryos that were mosaic for arrest in cycles 13 and 14 or cycles 14 and 15 (as in Fig. 7B,D), were counted as two data points.

threshold required for mitosis, and an interphase lag occurs during which cyclins must reaccumulate (Edgar et al. 1994b).

The second event in the chain reaction leading to the MZT is the activation of zygotic transcription. Activation of most genes appears to require slowing of the cell cycle in both Drosophila (Edgar and Schubiger 1986) and Xenopus embryos (Kimelman et al. 1987). This may be because transcription is mechanically suppressed by DNA replication and chromosome condensation (Shermoen and O'Farrell 1991; Rothe et al. 1992; Yasuda and Schubiger 1992), because transcriptional repressors are titrated out of the embryonic cytoplasm by the proliferating nuclei (Prioleau et al. 1994; Pritchard and Schubiger 1996), or because active Cdc2 kinase represses transcription by phosphorylating components of the transcription apparatus (Hartl et al. 1993). This last explanation is particularly attractive because transient inactivations of $\mathrm{Cdc} 2$ kinase are first detected around cycle 10 (Edgar et al. 1994b), just as general transcriptional activation begins (Edgar and Schubiger 1986). Re-
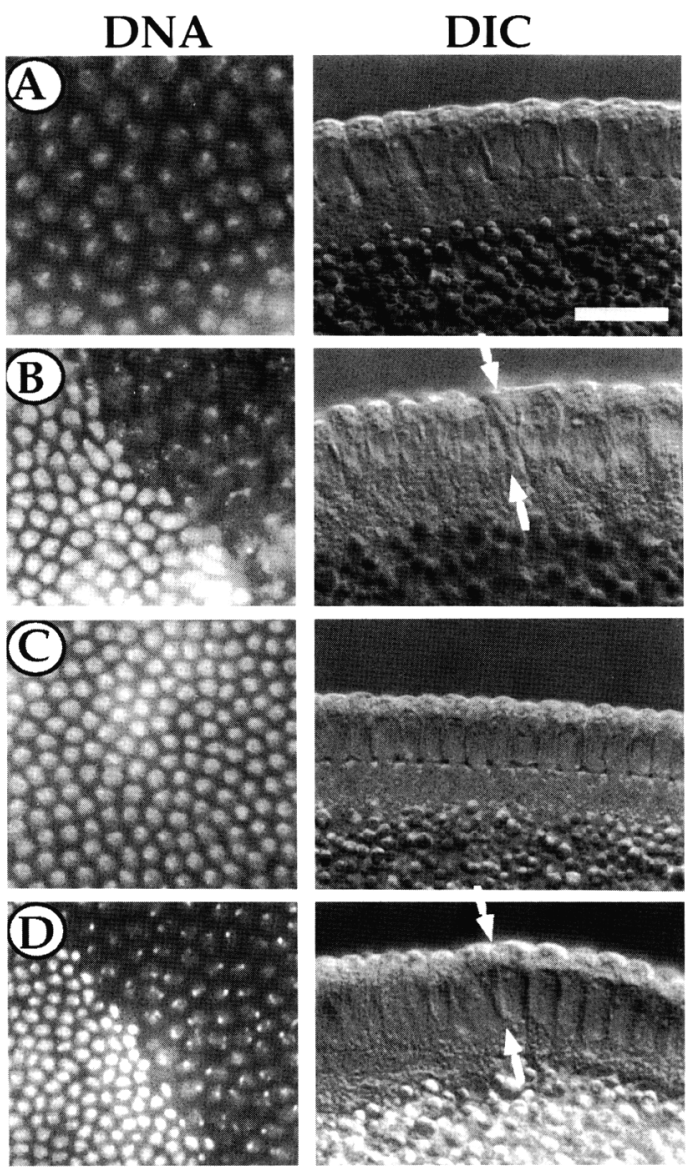

Figure 7. The MZT can occur one cell cycle early if maternal Cdc25 is reduced, and one cycle late if it is increased. (C) The density of nuclei (DNA; stained with Hoescht 33258) and size of cells at cellularization (DIC; differential interference contrast optics) in a wild-type cycle 14 embryo. $(A, B)$ Decreased nuclear densities and increased cell sizes in embryos produced by $1 x$ twine $0 x$ string germ lines. (B) A mosaic cycle $13 / 14$ arrest. $(D)$ A portion of a mosaic embryo produced by a $6 \mathrm{x}$ twine $2 \mathrm{x}$ string germ line, in which part of the blastoderm has arrested at cycle 14 and the other part at cycle 15. Arrows indicate the boundaries between different cell cycles in mosaic embryos. All photos are the same magnification. White scale bar in $A, 20 \mu \mathrm{m}$. 


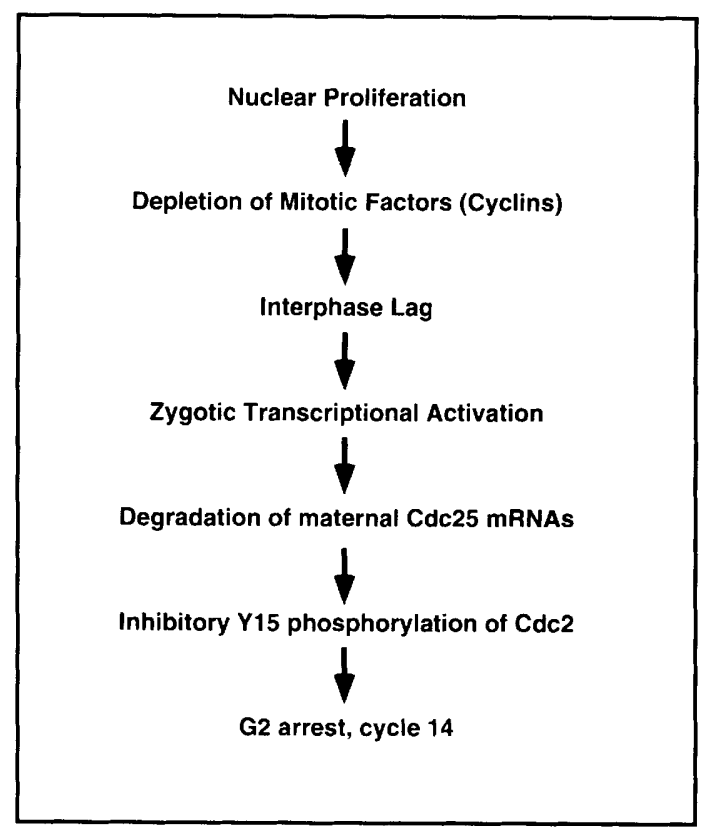

Figure 8. A summary of events leading to Drosophila's MZT.

gardless of which mechanism initiates transcription the result is the same: New gene products accumulate that promote degradation of maternal mRNAs including string and twine. This causes Cdc25 phosphatase activity to plummet and allows inhibitory phosphorylation of Cdc2 by the Dweel kinase, a constitutively expressed maternal product (Campbell et al. 1995). The result is cell cycle arrest in $\mathrm{G} 2_{14}$.

Although this proposed mechanism for the MZT is consistent with virtually all previous studies of the early Drosophila embryo, we should note that it is inconsistent with a recent report from Myers et al. (1995). This group tracked string mRNA stability after $\alpha$-amanitin treatment of early embryos but, in contrast to our results, found that string mRNA was not stabilized. We ascribe this inconsistency to the possibility that the method used for delivering $\alpha$-amanitin-embryo permeabilization rather than injection-did not inhibit transcription rapidly or completely enough to block the activation of the RNA degradation. In our own experiments we have noticed that embryos injected with $\alpha$-amanitin later than cycle 6 often fail to have an extra division and have incomplete stabilization of maternal Cdc25 mRNAs (not shown). This suggests that even small amounts of transcription are sufficient to trigger turnover of maternal mRNAs.

The mechanism that we propose for Drosophila's MZT has several properties that are advantageous for the embryo. First, the functional coupling of several reactions that are progressive (cyclin depletion, cycle slowdown, transcriptional activation, and RNA turnover) makes for a switch that will inactivate the maternal oscillator rapidly and discreetly within one cell cycle. The coincident acceleration of RNA turnover, elongation of $S$ phases, and the acquisition of an $S / M$ checkpoint creates a time window in cycle $14\left(45^{\prime}\right)$ that is ample for degradation of Cdc25 mRNAs, even when their levels are abnormally high. In contrast, the corresponding time window in cycle 13 is much shorter $\left(<18^{\prime}\right)$ and occurs when RNA turnover is much slower, making premature degradation of Cdc25 mRNAs improbable even when their levels are abnormally low. Thus the switch is relatively resistant to environmental or genetic variations that might alter the activity of its components (see Table 1).

As well as constituting a robust switch, the proposed coupled reaction mechanism may explain how Drosophila embryos add early cycles to compensate for lost or defective (nondividing) nuclei (Okada et al. 1980; Edgar et al. 1986; Yasuda et al. 1991). Coupling the activation of RNA turnover to nuclear proliferation allows $\mathrm{Cdc} 25$ mRNA degradation to be delayed when nuclei are lost in the early cycles, and thus ensures that the MZT will occur at the correct cell density even if more cycles are required to achieve this density. When compared to proposed mechanisms that count the number of cell cycles or the time elapsed from fertilization (Howe et al. 1995), this type of switch would seem to have a great selective advantage.

\section{Materials and methods}

\section{Injections}

Inhibitors (Sigma) were injected in an anteroposterior stripe at concentrations that completely and irreversibly blocked function of the target molecules: $\alpha$-amanitin at $500 \mu \mathrm{g} / \mathrm{ml}$; colcemid at $200 \mu \mathrm{g} / \mathrm{ml}$; and aphidicolin at $400 \mu \mathrm{g} / \mathrm{ml}$. (See Schubiger and Edgar (1994) for a complete description of microinjection methods and inhibitor effects.)

\section{RNA detection}

Northern blots were performed essentially as described by Edgar and Schubiger (1986). Embryos were staged live by microscopic observation and frozen, and total nucleic acid was extracted. After injections (Fig. 2A), only completely intact embryos were used because dead regions were found to be deficient in RNA turnover. Six embryos were loaded per gel lane. Digoxygenin (DIG)-labeled RNA probes and Lumi-Phos chemiluminescence (Boehringer-Mannheim) were used to detect mRNAs after hybridization. RNA levels were quantified from X-ray film using a Sharp JX-330 film scanner with no contrast enhancement and ImageQuant software. Signals were normalized to rp 49 mRNA to control for loading variation and quantified from multiple exposures to control for film and substrate saturation. A dilution series of string RNA confirmed that although not entirely linear, this method was adequate for rough quantitation (Fig. 9).

\section{Protein detection}

Immunoblots (Fig. 3A,B) were performed using lysates from 1-10 methanol-fixed embryos that were stained with the DNA dye Hoechst 33258 and staged posthumously as described in Edgar et al. (1994b) and Schubiger and Edgar (1994). Injected embryos (Figs. 2C, 4) were not methanol fixed but were staged live, frozen at $-70^{\circ} \mathrm{C}$, rinsed from the injection oil using heptane, transferred to tubes, and crushed directly into SDS sample buffer and boiled. Affinity-purified rabbit polyclonal antibodies 


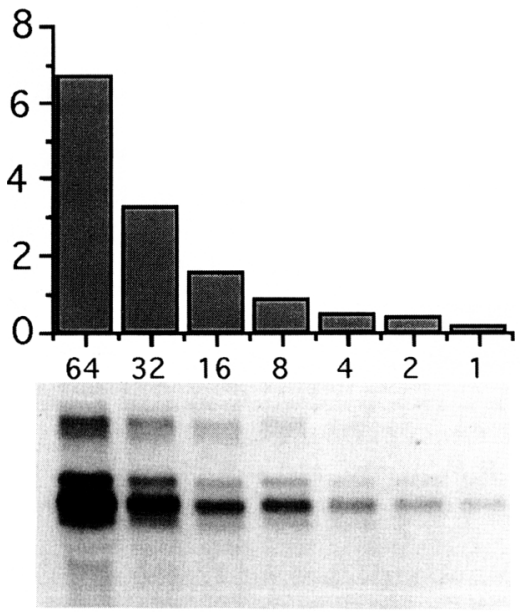

Figure 9. Quantitation of stg RNA using DIG/Lumi-Phos detection. To assess the linearity of the chemiluminescent method used to measure RNA levels from Northern blots (Figs. 2 and 3), we used a twofold dilution series (64-1) of embryo RNA probed for string. Multiple exposures of the blot shown were scanned and densitometrically quantified, giving the result shown. The method, though not strictly linear, was deemed satisfactory.

(AP4 or RbRf) were used to detect Cdc25 $5^{\text {string }}$ protein, and a mouse monoclonal antibody (Amersham) was used to detect $\beta$-tubulin. For detection on filters we used HRP-conjugated secondary antibodies (Amersham) and the ECL chemiluminescent technique. Protein quantitation was as described above. In situ detection was done using biotinylated secondary antibodies (Jackson) and streptavidin-conjugated HRP (Chemicon)

\section{Visual analysis of cell cycles}

Live embryos were dechorionated, affixed to slides, covered with halocarbon oil, and observed without coverslips using DIC optics and a $20 \times$ objective. Some cell cycle timing data was collected by observing 50-100 embryos in repeated series, such that the cell cycle stage of each embryo was scored once per 10 min. Cell cycle times were also measured by time-lapse video analysis using an MTI VE-1000 camera and a Mitsubishi HSS5600 VCR. Wild-type embryos were timed in parallel to control for variations in temperature, which was $21^{\circ} \mathrm{C}-23^{\circ} \mathrm{C}$. To assess nuclear densities, we fixed embryos with formaldehyde, stained them with Hoechst 33258, and observed them using a $40 \times$ objective and an ocular grid as described by Foe and Alberts (1983). Nuclei/grid square in two regions of each embryo were counted and then averaged for each value. Grid squares $=625$ $\mu \mathrm{m}^{2}$, as measured by a slide micrometer.

\section{Genetics and germ-line clone experiments}

Wild-type flies were of the Sevelen strain. Flies with four additional copies of a maternally expressed string transgene were of the genotype $w P / \mathrm{w}^{+}$stg15.3//W $\mathrm{P} / \mathrm{w}^{+}$stg15.3/; + ; $\mathrm{P} / \mathrm{w}^{+}$stg $31.3 \mathrm{~J} / \mathrm{P} / \mathrm{w}^{+}$stg31.3]. Flies with four additional copies of twine were of the genotype $\left.\left.w P / w^{+} t w n 3.7\right] / w P / w^{+} t w n 3.7\right] ;+$; $\left.P / w^{+} t w n 10.0\right] / P\left[w^{+} t w n 10.0\right]$. The maternal effect of string was tested by generating $\mathrm{stg} / \mathrm{stg}$ germ-line clones using the $F L P / F R T /$ ovO $^{D 1}$ mitotic recombination method as described by Chou et al. (1993). First- and second-instar larvae of the geno- type whs-FLP1/+; P/ry ${ }^{+}$hs-neo FRT]82B P/w ${ }^{+}$hs-M/87E stg ${ }^{-} / \mathrm{P} / \mathrm{ry}^{+}$hs-neo FRT $/ 82 \mathrm{~B} \mathrm{P} / \mathrm{w}^{+}$ovo $\mathrm{O}^{D 1} \mathrm{j}^{3 R}$ were heat-shocked twice for $2 \mathrm{hr}$ at $37^{\circ} \mathrm{C}$ on consecutive days to induce mitotic recombination. $O V O^{D 1}$ is a dominant female sterile mutation that blocks oogenesis, and thus only recombinant, stg/stg germ cells produce eggs using this method. About 200 recombinant females were crossed to either wild-type males, or to $w$; $\operatorname{stg}^{7 B} /$ TM3 Sb males to check for segregation of the $P / r^{+}{ }^{+} h s-n e o$ FRT $82 B P / W^{+}$hs $-M / 87 E$ stg $^{7 B}$ chromosome from females. Six different alleles of stg were tested according to this regime $17 B$, $9 A, 3 A 1, A R 2, A R 4, A R 5)$. Two, which are large deletions that affect neighboring transcription units $(A R 2, A R 5)$ resulted in female sterility. Germ lines homozygous for the other four alleles were very fertile. To generate $t w n / t w n ; s t g / s t g$ germlines we performed the following cross: $w$ hs $-F L P 1 / Y ; t w n^{H B 5} \mathrm{cn}$

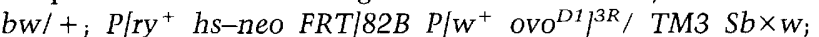
${ }_{t w n}^{H B S} \mathrm{cn} \mathrm{bw/CyO;P} / \mathrm{ry}^{+}$hs-neo FRT/82B P/w $/ \mathrm{w}^{+}$hs $-M / 87 E$ $s t g^{7 B} / T M 3 S b$. The progeny of this cross were heat-shocked as above and $\sim 200$ females of the genotype $w h s-F L P 1 / w ; t w n^{H B 5}$ cn bw/twn ${ }^{H B 5}$ cn bw; P/ry ${ }^{+}$hs-neo FRT $782 B P / w^{+}$hs $-M / 87 E$ $s t g^{7 B} / P\left[r^{+}{ }^{+} \text {hs-neo FRT } / 82 B P / W^{+} \text {ovo } O^{D 1}\right]^{3 R}$ were selected, crossed to wild-type males, and used for egg collections. To generate $t w n /+$; stg/stg germ lines, the same cross and heat shocks were performed, and females of the genotype $w$ hsFLP1/w; $\mathrm{twn}^{H B 5} \mathrm{cn} \mathrm{bw/+;P/ry}{ }^{+}$hs-neo FRT/82B P/W $/ \mathrm{w}^{+}$hs$M] 87 E$ stg $^{7 B} / P\left[\mathrm{ry}^{+}\right.$hs - neo $\left.F R T\right] 82 B P\left[\mathrm{~W}^{+} \text {ovo } \mathrm{O}^{D 1}\right]^{3 R}$ were selected and crossed to wild-type males.

\section{Acknowledgments}

We thank Luke Alphey for the gift of twine DNA and flies carrying twine transgenes, Pierre Leopold, Nikita Yakubovitch, and Pat O'Farrell for the hs-Cdc2-T14A, Y15F flies, Norbert Perrimon for FRT-ovo ${ }^{\mathrm{D} 1}$ flies, and Delia Lakich for her interest and preliminary work. We also thank Pat O'Farrell, Gerold Schubiger and his students, Tom Neufeld, Dara Lehman, Michele Garfinkel, and anonymous reviewers for comments on the manuscript. This work was supported by a grant from the $\mathrm{Na}$ tional Institutes of Health (RO1 GM51186), a Lucille P. Markey Scholar Award, and a Rita Allen Foundation Scholarship to B.A.E.

The publication costs of this article were defrayed in part by payment of page charges. This article must therefore be hereby marked "advertisement" in accordance with 18 USC section 1734 solely to indicate this fact.

\section{References}

Alphey, L., J. Jimenez, H. White-Cooper, I. Dawson, P. Nurse, and D.M. Glover. 1992. twine, a cdc25 homolog that functions in the male and female germline of Drosophila. Cell 69: 977-988.

Amon, A., S. Irniger, and K. Nasmyth. 1994. Closing the cell cycle circle in yeast: $\mathrm{G} 2$ cyclin proteolysis initiated at mitosis persists until the activation of Gl cyclins in the next cycle. Cell 77: 1037-1050.

Anderson, K.V. and J.A. Lengyel. 1979. Rates of synthesis of major classes of RNA in Drosophila embryos. Dev. Biol. 70: 217-231.

-1980. Changing rates of histone mRNA synthesis and turnover in Drosophila embryos. Cell 21: 717-727.

Bissen, S.T. 1995. Expression of the cell cycle control gene, 
cdc25, is constitutive in the segmental founder cells but is cell-cycle-regulated in the micromeres of leech embryos. $D e$ velopment 121: 3035-3043.

Campbell, S.D., B.A. Edgar, and P.H. O'Farrell. 1995. Drosophila Weel kinase rescues fission yeast from mitotic catastrophe and phosphorylates Drosophila Cdc2 in vitro. Mol. Biol. Cell 6: 1333-1347.

Chou, T.-B., E. Noll, and N. Perrimon. 1993. Autosomal P/ovoD1/ dominant female-sterile insertions in Drosophila and their use in generating germ-line chimeras. Development 119: 1359-1369.

Coleman, T.R. and W.G. Dunphy. 1994. Cdc2 regulatory factors. Curr. Opin. Cell Biol. 6: 877-882.

Courtot, C., C. Fankhauser, V. Simanis, and C.F. Lehner. 1992. The Drosophila cdc25 homolog twine is required for meiosis. Development 116: 405-416.

Dasso, M. and J.W. Newport. 1990. Completion of DNA replication is monitored by a feedback system that controls the initiation of mitosis in vitro: Studies in Xenopus. Cell 61: $811-823$.

Debec, A., R.F. Kalpin, D.R. Daily, P.D. McCallum, W.F. Rothwell, and W. Sullivan. 1996. Live analysis of free centrosomes in normal and aphidicolin-treated Drosophila embryos. J. Cell Biol. (in press).

Edgar, B.A. and P.H. O'Farrell. 1989. Genetic control of cell division patterns in the Drosophila embryo. Cell 57: 177187.

- 1990. The three postblastoderm cell cycles of Drosophila embryogenesis are regulated in G2 by string. Cell 62: $469-480$.

Edgar, B.A. and G. Schubiger. 1986. Parameters controlling transcriptional activation during early Drosophila development. Cell 44: 871-879.

Edgar, B.A., C.P. Kiehle, and G. Schubiger. 1986. Cell cycle control by the nucleo-cytoplasmic ratio in early Drosophila development. Cell 44: 365-372.

Edgar, B.A., D. Lehman, and P.H. O'Farrell. 1994a. Cis-acting sequences of string (cdc25): A link between developmental programming and the cell cycle. Development 120: 31313143.

Edgar, B.A., F. Sprenger, R.J. Duronio, P. Leopold, and P.H. O'Farrell. 1994b. Distinct molecular mechanisms regulate cell cycle timing at successive stages of Drosophila embryogenesis. Genes \& Dev. 8: 440-452.

Edgar, L.G., N. Wolf, and W.B. Wood. 1994. Early transcription in Caenorhabditis elegans embryos. Development 120: 443-451.

Ferrell, J.E., M. Wu, J.C. Gerhart, and G.S. Martin. 1991. Cell cycle tyrosine phosphorylation of $\mathrm{p} 34 \mathrm{Cdc} 2$ and a microtubule associated protein kinase homolog in Xenopus oocytes and eggs. Mol. Cell. Biol. 11: 1965-1971.

Finley, R.L., Jr., B.J. Thomas, S.L. Zipursky, and R. Brent. 1996. Isolation of Drosophila Cyclin D; a protein expressed in the morphogenetic furrow before entry into S phase. Proc. Natl. Acad. Sci. 93: 3011-3015.

Foe, V.E. 1989. Mitotic domains reveal early commitment of cells in Drosophila embryos. Development 107: 1-22.

Foe, V.E. and B.M. Alberts. 1983. Studies of nuclear and cytoplasmic behaviour during the five mitotic cycles that precede gastrulation in Drosophila embryogenesis. /. Cell Sci. 61: 31-70.

Foe, V.E., G.M. O'Dell, and B.A. Edgar. 1993. Mitosis and morphogenesis in the Drosophila embryo: Point and counterpoint. In The development of Drosophila melanogaster (ed. M. Bate and A. Martinez-Arias), pp. 149-300. Cold Spring
Harbor Laboratory Press, Cold Spring Harbor, NY.

Frederick, D.L. and M.T. Andrews. 1994. Cell cycle remodeling requires cell-cell interactions in developing Xenopus embryos. J. Exp. Zool. 270: 410-416.

Hartl, P., J. Gottesfeld, and D.J. Forbes. 1993. Mitotic repression of transcription in vitro. J. Cell Biol. 120: 613-624.

Hoffmann, I. and E. Karsenti. 1994. The role of cdc25 in checkpoints and feedback controls in the eukaryotic cell cycle. $J$. Cell Sci. (Suppl.) 18: 75-79.

Howe, J.A., M. Howell, T. Hunt, and J.W. Newport. 1995. Identification of a developmental timer regulating the stability of embryonic cyclin A and a new somatic A-type cyclin at gastrulation. Genes \& Dev. 9: 1164-1176.

Kane, D.A., R.M. Warga, and C.B. Kimmel. 1992. Mitotic domains in the early embryo of the zebrafish. Nature 360: 735737.

Kimelman, D., M. Kirschner, and T. Scherson. 1987. The events of the midblastula transition in Xenopus are regulated by changes in the cell cycle. Cell 48: 399-417.

Knoblich, J.A., K. Sauer, L. Jones, H. Richardson, R. Saint, and C.F. Lehner. 1994. Cyclin E controls S-phase progression and its down-regulation during Drosophila embryogenesis is required for the arrest of cell proliferation. Cell 77: 107-120.

Kobayakawa, Y. and H. Kubota. 1981. Temporal pattern of cleavage and the onset of gastrulation in amphibian embryos developed from eggs with the reduced cytoplasm. I. Embryol. Exp. Morphol. 62: 83-94.

Lehner, C.F. and P.H. O'Farrell. 1989. Expression and function of Drosophila cyclin A during embryonic cell cycle progression. Cell 56: 957-968.

1990a. Drosophila cde2 homologs: A functional homolog is coexpressed with a cognate variant. EMBO $\%$ 9: $3573-3581$.

- 1990b. The roles of Drosophila cyclins A and B in mitotic control. Cell 61: 535--547.

Mita, I. 1983. Studies on factors affecting the timing of early morphogenetic events during starfish embryogenesis. J. Exp. Zool. 225: 293-299.

Mita, I. and C. Obata. 1984. Timing of early morphogenetic events in tetraploid starfish embryos. J. Exp. Zool. 229: 215222.

Myers, F.A., H. Francis-Lang, and S.F. Newbury. 1995. Degradation of maternal string mRNA is controlled by proteins encoded on maternally contributed transcripts. Mech. Dev. 51: 217-226.

Newport, J. and M. Kirschner. 1982a. A major developmental transition in Xenopus embryos: I. Characterization of timing of cellular changes at the midblastula stage. Cell 30: 675686.

_ 1982b. A major developmental transition in Xenopus embryos: II. Control of the onset of transcription. Cell 30: 687-696.

O'Farrell, P. H., B.A. Edgar, D. Lakich, and C.F. Lehner 1989. Directing cell division during development. Science 246: 635-640.

Okada, M., H. Komatsu, and M. Okumura. 1980. Behavior of interphase embryonic nuclei transplanted in nuclear multiplication stage embryos of Drosophila. Growth Differ. 22: 599-610.

Prioleau, M.N., J. Huet, A. Sentenac, and M. Mechali. 1994. Competition between chromatin and transcription complex assembly regulates gene expression during early development. Cell 77: 439-449.

Pritchard, D.K. and G. Schubiger. 1996. Activation of transcription in Drosophila embryos is a gradual process mediated by 
the nucleocytoplasmic ratio. Genes \& Dev. 10: 1131-1142.

Raff, J.W. and D.M. Glover. 1988. Nuclear and cytoplasmic mitotic cycles continue in Drosophila embryos in which DNA synthesis is inhibited with aphidicolin. J. Cell Biol. 107: 2009-2019.

Rothe, M., M. Pehl, H. Taubert, and H. Jäckle. 1992. Loss of gene function through rapid mitotic cycles in the Drosophila embryo. Nature 359: 156-159.

Sauer, K., J.A. Knoblich, H. Richardson, and C.F. Lehner. 1995. Distinct modes of cyclin $\mathrm{E} / \mathrm{cdc} 2 \mathrm{c}$ kinase regulation and S-phase control in mitotic and endoreduplication cycles of Drosophila embryogenesis. Genes \& Dev. 9: 1327-1339.

Schubiger, G. and B. Edgar. 1994. Using inhibitors to study embryogenesis. Drosophila melanogaster: Practical uses in cell biology. Methods Cell Biol. 44: 697-713.

Schultz, R.M. 1993. Regulation of zygotic gene activation in the mouse. BioEssays 15: 531-538.

Shermoen, A.W. and P.H. O'Farrell. 1991. Progression of the cell cycle through mitosis leads to abortion of nascent transcripts. Cell 67: 1-20.

Smythe, C. and J.W. Newport. 1992. Coupling of mitosis to the completion of $S$ phase in Xenopus occurs via modulation of the tyrosine kinase that phosphorylates p34 ${ }^{\mathrm{cdc} 2}$. Cell 68: 787-797.

Stern, B., G. Ried, N.J. Clegg, T.A. Grigliatti, and C.F. Lehner. 1993. Genetic analysis of the Drosophila cdc2 homolog. Development 117: 219-232.

Weigmann, K. and C.F. Lehner. 1995. Cell fate specification by even-skipped expression in the Drosophila nervous system is coupled to cell cycle progression. Development 121: 3713-3721.

White-Cooper, H., L. Alphey, and D.M. Glover. 1993. The cdc25 homologue twine is required for only some aspects of the entry into meiosis in Drosophila. I. Cell Sci. 106: 10351044.

Wickramasinghe, D., S. Becker, M.K. Ernst, J.L. Resnick, J.M. Centanni, L. Tessarollo, L.B. Grabel, and P.J. Donovan. 1995. Two CDC25 homologues are differentially expressed during mouse development. Development 121: 1283-1299.

$\mathrm{Xu}, \mathrm{T}$. and G.M. Rubin. 1993. Analysis of genetic mosaics in developing and adult Drosophila tissues. Development 117: 1223-1237.

Yasuda, G.K. and G. Schubiger. 1992. Temporal regulation in the early embryo: Is MBT too good to be true? Trends Genet. 8: 124-127.

Yasuda, G.K., J. Baker, and G. Schubiger. 1991. Temporal regulation of gene expression in the blastoderm Drosophila embryo. Genes \& Dev. 5: 1800-1812. 


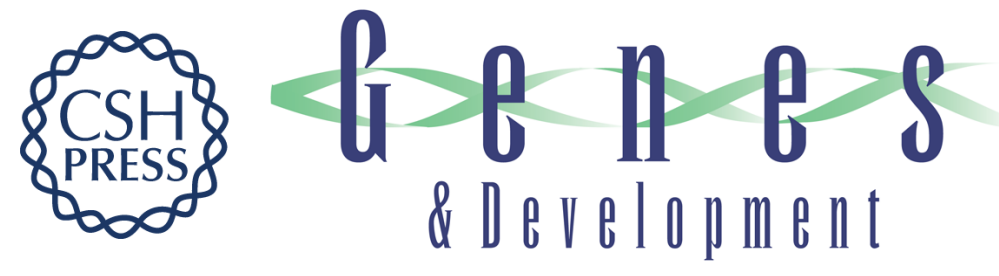

\section{Zygotic degradation of two maternal Cdc25 mRNAs terminates Drosophila's early cell cycle program.}

B A Edgar and S A Datar

Genes Dev. 1996, 10:

Access the most recent version at doi:10.1101/gad.10.15.1966

References This article cites 55 articles, 23 of which can be accessed free at:

http://genesdev.cshlp.org/content/10/15/1966.full.html\#ref-list-1

License

Email Alerting

Service

Receive free email alerts when new articles cite this article - sign up in the box at the top right corner of the article or click here.

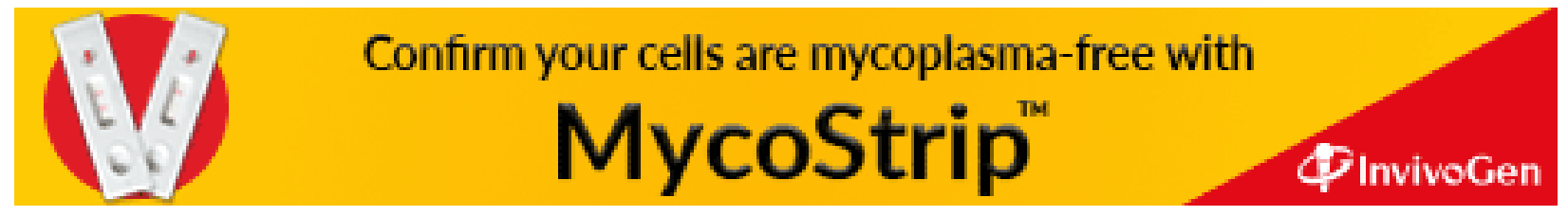

